\title{
Relações parentais no futebol de salão: a experiência do Paulista Futebol Clube
}

\author{
Luiz Carlos Rigo" \\ Márcio Xavier Bonorino Figueiredo** \\ Gabriel Barros da Cunha*** \\ Gicele de Oliveira Karini ${ }^{* * * *}$
}

\begin{abstract}
Resumo: Esta pesquisa tem como objetivo analisar a participação e as práticas de intervenção dos pais junto às escolinhas de futebol de salão - "futsal". Para realizar o estudo, utilizamos o método da "Participação Observante", e alguns princípios oriundos da História Oral. O foco empírico do estudo foi a equipe de Iniciação (8 e 9 anos) do Paulista Futebol Clube. Apesar de a participação desmedida dos pais interferir no trabalho do professor concluímos que ela porta certas positividades fundamentais na educação infantil, cabendo aos professores o desafio de aprender a lidar com ela.
\end{abstract}

Palavras-chave: Futebol de salão. Criança. Relações Pais-Filho. Comportamento competitivo.

\section{INTRODUÇÃO}

Episódio 1: Em 1992 estávamos em Porto Alegre, eu (Gabriel) e meu pai, para assistir aos jogos da equipe do Caixeiral na categoria pré-mirim. Na final, começou uma confusão entre os pais nas arquibancadas que só acabou com a chegada da Brigada Militar que retirou todos do ginásio e ordenou que o jogo prosseguisse sem torcida.

Episódio 2: A categoria mirim do Paulista F. C. viajava para jogar em Caxias do Sul. Além das crianças e dos professores iam também alguns pais. Num certo momento da viagem, em função de

\footnotetext{
* Doutor em Educação pela UNICAMP, professor da ESEF/UFPel. Líder do Grupo de Pesquisa Estudos Culturais em Educação Física (CNPq). E-mail: Icrigo@terra.com.br

** Doutor em Educação pela USP, professor da ESEF/UFPel. Membro do Grupo de Pesquisa Estudos Culturais em Educação Física (CNPq). E-mail: bonorino.sul@terra.com.br

*** Professor Licenciado em Educação Física pela ESEF/UFPel, mestrando em Educação Física pela Universidade do Porto, Portugal. Membro do Grupo de Pesquisa Estudos Culturais em Educação Física (CNPq). E-mail: gabrielcunha_rs@hotmail.com

**** Acadêmica de Educação Física na ESEF/UFPel, membro do Grupo de Pesquisa Estudos Culturais em Educação Física (CNPq). E-mail: gicelikarini@hotmail.com.
} 


\section{Astigos Originais}

Luís Carlos Rigo, et al.

um cigarro, a mãe do goleiro reserva e a do titular iniciaram uma discussão que quase acabou em agressões físicas.

Iniciamos o nosso estudo com esses dois relatos porque, apesar de serem situações extremas, eles falam de aspectos importantes que estão presentes nas formas de participação dos pais nas equipes de escolinhas de futsal, fato que ocorre diariamente e que os professores encontram dificuldades em administrar.

Para estudarmos a participação dos pais, tomamos como referência as seguintes questões: quais são as principais formas de intervenções dos pais? Onde e como elas ocorrem? Como os pais avaliam a sua participação? Como as crianças concebem a participação dos pais? Quais os objetivos dos pais ao matricularem seus filhos em uma equipe de futsal? E, por último, como os professores lidam com a presença dos pais? Ela é apenas negativa ou contempla também positividades?

\section{APONTAMENTOS TEÓRICOS E METODOLÓGICOS}

Em função dos objetivos e da natureza desta pesquisa, optamos por delimitar o campo empírico do estudo na categoria Iniciação (entre 8 e 9 anos) da equipe da escolinha do Paulista Futebol Clube. Esta escolha deu-se, prioritariamente, por dois motivos: primeiro, pelo fato de o Paulista ser um dos clubes de maior tradição no futsal da cidade; e segundo pela proximidade que temos com o clube e com a categoria escolhida, o que facilitou a coleta de dados para a realização do estudo. ${ }^{1}$

Utilizamos predominantemente a metodologia da etnografia, mais especificamente a proposta etnográfica que Loïc Wacquant (2002) chamou de "Participação Observante". ${ }^{2}$ Nesse sentido, coletamos uma série de observações durante os treinos, os jogos e as

1 Um dos autores, Gabriel Cunha, foi atleta do clube e, no período que os dados desta pesquisa
foram coletados (2004 e 2005), era o professor da equipe que foi objeto do estudo.
${ }^{2}$ O termo "Participação Observante" é utilizado pelo autor para demarcar um deslocamento
metodológico diante da clássica "Observação Participante", oriundas das pesquisas
etnográficas. Loïc Wacquant salienta que a diferença central está no fato de a "Participação
Observante" ter uma maior intervenção, uma vivência corporal, uma experimentação do
pesquisador com a prática cultural (objeto) que ele está investigando. No nosso caso, isso
esteve presente pelo fato de Gabriel ser o próprio professor da equipe que estudamos.

Movimento, Porto Alegre, v.13, n. 02, p.77-90, maio/agosto de 2007. 
viagens da equipe ao longo de 2004 e 2005. Essas observações foram registradas em um caderno e enriquecidas com algumas fotografias. Além dos episódios que avaliamos como importantes e representativos para o estudo (certos jogos), registramos também alguns acontecimentos do cotidiano. Além desses registros realizamos quatro entrevistas: três com pais de alunos e uma com um professor de Educação Física que trabalha com futsal há mais de 10 anos e já atuou no Paulista F. C. em diferentes categorias. Também aplicamos um questionário nas dez crianças que fazem parte da equipe estudada. Esse questionário foi composto por perguntas simples e diretas e foi utilizado para termos alguns indicadores sobre a opinião das crianças quanto à participação dos pais. A preparação e a estrutura das entrevistas seguiram os procedimentos adotados nas metodologias qualitativas de Triviños (1987) e Gatti (2002). O uso das entrevistas e das demais fontes orais que são citadas no decorrer do estudo segue os princípios adotados pela Metodologia da História Oral, que podem ser encontrados em autores como Thompson (1992), Ferreira (2000) e Amado (1998).

Os autores que serviram de suporte teórico para este artigo foram utilizados como se fossem uma espécie de "caixa de ferramentas", ${ }^{3}$ no sentido atribuído por Foucault, ou seja, fizemos referências a eles somente quando avaliamos que os mesmos poderiam contribuir especificamente para aquelas questões que estavam sendo tratadas. Ao comentar sobre o valor da teoria e a metodologia que utiliza para selecionar certos autores que lhe fazem companhia, Michel Foucault (1979, p. 143) salienta: “[...] os autores que eu gosto, eu os utilizo". Sobre Nietzsche, especificamente, ele acrescenta: "O único sinal de reconhecimento que se pode ter para com um pensamento como o de Nietzsche, é precisamente utilizá-lo, deformá-lo, fazê-lo ranger, gritar".

Assim, por uma opção epistemológica e metodológica, o artigo não apresenta uma sessão teórica separada das fontes empíricas. Mais do que uma teoria ou um autor que servisse de referência

\footnotetext{
${ }^{3}$ Sobre como Foucault utiliza autores, ver: JÓDAR, Francisco; GÓMEZ, Lucía. Experimentar o presente: sobre a conformação de novas identidades. Educação \& Realidade: Dossiê Michel Foucault, Porto Alegre, v. 29, n. 1, p.139-153, jan./jun. 2004.

Movimento, Porto Alegre, v.13, n. 02, p.77-90, maio/agosto de 2007.
} 
exclusiva, o que fizemos foi nos apropriarmos de contribuições específicas de vários autores. Como diria Gilles Deleuze (2000, p.17), realizamos "[...] uma leitura em intensidade [do tipo] 'ligação elétrica', para falarmos das práticas das escolinhas de futsal "[...] por afectos, intensidades, experiência, experimentações" (DELEUZE, 2000, p. 15).

\section{PAULISTA F. C.: UM CLUBE DE TRADIÇÃO}

O Paulista Futebol Clube, fundado em 27 de julho de 1942, ${ }^{4}$ inicialmente era voltado para a prática do futebol de campo e, a partir de 1958, começou a dedicar maior atenção ao futsal até alcançar projeção em Pelotas e no Rio Grande do Sul. Nos últimos anos o Clube foi acumulando títulos estaduais e citadinos em diferentes categorias e tornou-se um dos poucos clubes do estado campeão em todas as categorias, da iniciação ao adulto. Se tomarmos com referência todas as categorias, o Paulista é o clube da cidade de Pelotas com o maior número de títulos dentro do futsal. Na última década, ele venceu $70 \%$ das competições citadinas que disputou e ainda revelou atletas para o futebol de campo profissional. Pelo Clube já passaram jogadores como Émerson, da Seleção Brasileira, e Daniel Carvalho, que jogou no Internacional e também teve passagem pela Seleção.

Esse repertório merece destaque pela relação que ele possui com este estudo. No questionário que aplicamos às crianças, quando perguntamos a elas de quem tinha sido a escolha pelo clube, oito afirmaram que tinha sido sua e as outras duas que tinha sido de seus pais. Na sequiência indagamos o motivo principal dessa escolha. De dez, cinco nos responderam que era porque o clube possuía bons times. Nas entrevistas com os pais, esse motivo também apareceu. Um deles ressaltou: "“...] coloquei ele no Paulista por ser um clube de tradição e de formação de bons jogadores. Quero que ele tenha uma boa base para quando chegar aos treze anos poder jogar futebol de campo no Inter ou no Grêmio" (F. P., 2004).

${ }^{4}$ Entre os principais fundadores estão Ramon Abeijoun, Manoel Ribeiro, Fernando Martins, Francisco Coutinho, João Bróxidez, Jorge Garcias e Breno Monjeone (Informação oral de Carlos Carvalho, Patrono do Clube).

Novimento, Porto Alegre, v.13, n. 02, p.77-90, maio/agosto de 2007. 


\section{PRINCÍPIOS PEDAGÓGICOS E EXPECTATIVAS}

Jogar em um clube de projeção estadual, por onde passaram jogadores famosos, é um ingrediente a mais nas expectativas dos pais e das crianças, de conseguir sucesso no futebol profissional. Em uma pergunta que fizemos às crianças, indagamos sobre qual a profissão que os seus pais gostariam que elas seguissem. De dez, oito responderam que era a de jogador de futebol profissional. Esse sonho de ser jogador de futebol, que já faz parte do imaginário e da cultura infantil, quando intensificado pelas expectativas e esperanças parentais e pela mídia faz aumentar a cobrança por resultados técnicos imediatos. Assim, na ânsia em ver progressões técnicas e táticas, muitos pais cobram dos professores uma similitude maior com os métodos usados nos treinos das equipes adultas de futebol, pressionando os professores. Como disse uma mãe que estava acompanhando um treino: "[...] eles perdem muito tempo do treino brincando" (R. M., mãe de S. M., 2004).

Apesar da distância existente entre as escolinhas e as equipes profissionais, principalmente quanto aos resultados físico, técnico e tático, não raro vemos ocorrer uma reprodução dos estilos e métodos de trabalhos utilizados nas equipes de atletas profissionais para dentro das escolinhas de futsal, tornando os trabalhos um tanto repetitivos e monótonos. Preocupado com esta realidade, Ricardo Rezer $(2005)^{5}$ alerta sobre as conseqüências negativas oriundas desta predominância de proposta clubista nas metodologias de trabalhos das escolinhas que ele analisou. Segundo Jorge Bento (1989), se os professores não tomarem os devidos cuidados, esta tendência pode ter um efeito inverso do pretendido, afastando muitas crianças do esporte. Máximo Pimenta (2000) em seu artigo "Novos processos de formação de jogadores de futebol e o fenômeno das 'escolinhas': uma análise crítica do possível", denuncia a forma pela qual algumas escolhinhas privadas utilizam-se da mídia e fazem uso de nomes de ex-jogadores para capturar o imaginário infantil e seduzir pais e crianças com a promessa de formarem jogadores

${ }^{5}$ Para uma análise crítica mais detalhada sobre as metodologias de trabalhos predominante nas escolinhas de Futsal e os seus vínculos com os métodos de treinamento utilizados nas equipes adultas, consultar: REZER, Ricardo; SAAD, Michel. Futebol e futsal: possibilidades e limitações da prática pedagógica em escolinhas. Chapecó: Argos, 2005.

Movimento, Porto Alegre, v.13, n. 02, p.77-90, maio/agosto de 2007. 
profissionais de futebol, aumentando assim o número de alunos e, consequentemente, seus lucros.

Cabe deixar claro que não estamos advogando que as crianças devam deixar as escolinhas de futebol, tampouco somos adeptos dos velhos discursos que pregam contra a competição e o esporte na infância. Temos claro que, a cada dia, as crianças têm um contato maior com o esporte e com o futebol esportivizado e acreditamos que, quando tomados certos cuidados éticos, estéticos e pedagógicos, as competições esportivas, principalmente por tratarem da vitória e da derrota, têm muito a contribuir para a construção de uma subjetividade infantil menos onipotente. Como analisou Nilda Teves (1995, p. 52), “[...] perder, para muitas crianças, significa um grande abalo, pois convivem com a crença na possibilidade de terem o poder e o controle sobre todas as coisas e pessoas". Para outras, prossegue a autora, "[...] significa um grande sofrimento, por não conseguirem corresponder às cobranças domésticas por um desempenho sempre vitorioso". Por isso, justifica a autora, “[...] o jogo é também uma excelente pista desveladora dos processos de socialização e suas distorções, podendo auxiliar na orientação educativa para a vida em sociedade" (TEVES, 1995, p. 52-53). ${ }^{6}$

\section{PROFESSORES, PAIS E FILHOS: UM ENCONTRO NECESSÁRIO}

\begin{abstract}
Encontramos muitos exemplos de pais ou de mães que, projetando em seu filho desejos e projetos compensatórios, pedem-lhe o impossível. Aqui está uma das maiores fontes de contradições e de sofrimentos: um grande número de pessoas sofre continuamente com o desnivelamento entre suas conquistas e as expectativas parentais que não podem nem satisfazer nem repudiar. (BOURDIEU, 1997, p. 10)
\end{abstract}

\begin{abstract}
${ }^{6}$ Maiores considerações sobre como o futebol é capaz de intervir na sociabilidade de crianças e jovens das classes populares, consultar: DECCACHE-MAIA, E. Esporte e juventude no Borel. Revista Estudos Históricos, v. 13 n. 23, p. 192-206, Rio de Janeiro, Fundação Getúlio Vargas, 1999; RIGO, L. C. et al. Futebol à tardinha: notas sobre educabilidade. In: RIGO, L. C.; Pardo, E. R.; THOMAZ, F. O. (Org.) Além da Universidade... ljuí: Unijuí, 2006. p. 47-62; GUEDES, S. L. A construção do corpo masculino nas escolinhas de futebol. In: GUEDES, S. L. O Brasil no campo de futebol: estudos antropológicos sobre os significados do futebol brasileiro, Niterói: EDUFF, 1988. p. 117-136
\end{abstract}

Movimento, Porto Alegre, v.13, n. 02, p.77-90, maio/agosto de 2007. 
Não resta dúvida sobre a importância da participação dos adultos, e em especial dos pais, no desenvolvimento e na construção da subjetividade infantil, porém, nas equipes de futsal com crianças é comum identificarmos pais que têm dificuldades para estabelecer limites para a sua participação. Ao comentarmos sobre isso com uma mãe, ela nos disse que no ano anterior, de 2003, ela e seu marido haviam se envolvido tanto na outra equipe de futebol da qual seu filho participava que custearam boa parte das despesas do grupo. "Eu não conseguia dormir porque ficava pensando nas contas dos jogos para pagar, quase não via o D. P. jogar" (C. P., 2004). Gomes (2004) salienta que o envolvimento parental desmedido, tanto de tempo como de dinheiro, pode produzir sensações de ansiedade e de excesso de responsabilidade nas crianças, levando algumas ao abandono da prática esportiva.

A atenção maior dos pais costuma estar mais voltada para o seu filho e menos para o grupo do qual ele participa. Isso pode ser notado na hora de definir quais serão os titulares e quais serão os reservas, no momento das substituições durante uma partida ou mesmo na hora de estabelecer as posições de cada um dentro do time. Nesse ponto, chamou atenção a conversa que uma mãe teve conosco. Durante mais ou menos 30 minutos ela tentou convencer-nos de que o seu filho deveria ser titular de qualquer jeito, usando como argumento o tempo que ele jogava no clube, a opinião que ela ouvia de outras pessoas, além do desempenho que o menino tinha tido no último treino. Por fim, a mãe salientou que caso seu filho não fosse titular, ela não o levaria ao próximo jogo.

As tentativas de influenciar nas decisões do professor acontecem por telefone, após os treinos e também durante os jogos, como ocorreu em uma partida na qual o Paulista jogava contra seu principal rival nesta categoria. Quando faltavam seis minutos para terminar a partida, a mãe de L. C. se dirigiu até o banco de reservas e começou: "Tu tens que arriscar! Mexe no time! Faça alguma coisa se não nós vamos perder!". Nesse mesmo instante, a mãe de D. P. também se dirigiu até o banco de reservas e gritou: "Pombas cara! Agora que o D. P. tinha voltado a jogar bem, tu saca ele do time. Tu não queres mais o D. P. no teu time mesmo!". Essa insistência em interferir de um jeito ou de outro no trabalho do professor em pleno momento de jogo, e na presença de todas as crianças, além de aumentar a tensão

Movimento, Porto Alegre, v.13, n. 02, p.77-90, maio/agosto de 2007. 


\section{Antifos Originais}

Luís Carlos Rigo, et al.

da disputa e gerar atritos no grupo, dificulta e atrapalha o trabalho do professor.

Parte dessa postura pode estar relacionada com a forma como os pais acompanham o futebol de seus filhos. Quando perguntamos às crianças sobre como elas vão aos treinos, apenas uma respondeu que vai sozinha, as outras nove disseram que vão com os seus pais. Quando sondamos se os pais acompanham os treinos, cinco responderam que eles vão sempre, três que vão às vezes e duas que eles raramente vão. Aos jogos, nove responderam que os pais costumam ir sempre e apenas uma respondeu que seus pais vão raramente.

A dificuldade dos pais em estabelecer um distanciamento mínimo perante o trabalho do professor é uma característica comum nos trabalhos de equipes de futebol com crianças. Na entrevista que realizamos com o professor, ele nos contou que já havia enfrentado diversas vezes situações assim, e salientou que:

[...] pai é sempre passional, ele sempre acha que o seu filho é o melhor, que ele poderia ter sido utilizado mais frequientemente. Ele não tem a visão que o professor tem da equipe. São poucos os pais que conseguem compreender e deixar que o profissional faça o seu trabalho. (J. D. F., 2004)

Santana (1996) alerta para o fato de determinadas intervenções dos pais, principalmente pelo significado que eles possuem para seus filhos, deslegitimarem a autoridade pedagógica do professor, comprometendo o processo de constituição das subjetividades infantis.

Outro ponto polêmico e complexo presente na relação parental é a projeção dos desejos e das expectativas pessoais que muitos pais colocam em seus filhos. Rogério Voser (1999), por exemplo, chama atenção para o fato disso se manifestar com certa frequiência dentro do esporte. Nas entrevistas que realizamos com os pais, ao tratar desse tema identificamos duas posturas diferentes sobre como eles lidam com esta questão: a primeira partiu de um pai que jogou futebol na infância e na adolescência e que ressaltou que se preocupa e que procura ter cuidado para não projetar no filho os seus desejos; a segunda foi expressa por um pai que disse não ter

Movimento, Porto Alegre, v.13, n. 02, p.77-90, maio/agosto de 2007. 
um envolvimento maior com o futebol, esse explicitou que escolheu o Paulista para colocar seu filho principalmente por julgar que nesse clube ele teria maior possibilidade de chegar a ser um jogador profissional.

Tendo como referência as duas declarações acima, o que constatamos em nosso estudo foi que, ao contrário do que muitos pensam e comentam, os pais que possuem alguma experiência ou um maior conhecimento do futebol são aqueles que tendem a ter mais cuidado com as cobranças ou com as expectativas exageradas de seus filhos tornarem-se jogadores profissionais. O pai de B. A. (9 anos) é um exemplo disso. Em sua entrevista, ele passou um pouco desse entendimento, dessa sensibilidade dizendo:

\begin{abstract}
Não tem uma coisa assim que eu exteriorize pra ele, porque tem que fazer assim, tem que fazer assado, que eu vejo que tem pais que em treinos ficam possuídos quando o guri erra e tal, mas eu acho que tudo bem, até porque eu tive envolvido com isso, e eu tenho bem essa noção [...] têm vinte jogadores num grupo de Juniores num clube de futebol, desses, dez têm condições de seguir jogando futebol, desses dez, três vão ter a oportunidade de subir pra equipe principal, desses três, um deles vai ser aquele que o treinador, por algum motivo, vai colocar no time. (C. A., 2004)
\end{abstract}

O que observamos sobre a projeção dos pais nos seus filhos difere um pouco daquilo que alguns autores afirmam. Rogério Voser (1999), por exemplo, salienta que uma das causa da pressão dos pais sobre os filhos são as frustrações que eles trazem e projetam sobre os filhos, por terem sido "quase atletas". Apesar de isso ser uma possibilidade, consideramos que ela não pode ser tomada com uma afirmação universal, que leva a pressupor que os pais que tiveram uma vivência com o esporte teriam uma maior tendência em projetar suas expectativas esportivas sobre seus filhos, e coloca os outros pais (sem maior passagem pelo mundo esportivo) em uma posição mais amena. Em nosso estudo percebemos que o oposto também pode ocorrer e que as experiências esportivas dos pais também podem auxiliá-los a compreenderem que projeções desmedidas poderiam ser prejudiciais aos seus filhos.

Movimento, Porto Alegre, v.13, n. 02, p.77-90, maio/agosto de 2007. 


\section{Antifos Originais}

Luís Carlos Rigo, et al.

Esta controvérsia mostra que o tema da projeção dos pais sobre os filhos, apesar de ser bastante recorrente na psicologia, ainda foi pouco estudado especificamente no âmbito esportivo, carecendo de pesquisas empíricas de maior fôlego, principalmente no Brasil. ${ }^{7}$

\section{CONSIDERAÇÕES FINAIS}

Após a realização deste estudo, concluímos que a participação dos pais nas equipes de escolinhas de futsal é evidente, intensa e inevitável, principalmente nas categorias menores (iniciação, pré-mirim e mirim). Mais do que reclamar, os professores necessitam aprender a conviver e a lidar com ela, precisam buscar estratégias metodológicas que sejam capazes de resgatar as positividades e evitar os excessos que costumam estar presentes na participação dos pais.

Em relação aos pais, podemos ressaltar que na maioria das vezes a sua participação é bem-vinda e requerida pelas crianças. Todavia, ela adquire maior positividade quando respeita a proposta de trabalho do professor. Cabe também destacar que a participação e as múltiplas formas de intervenções parentais que acontecem trazem maiores contribuições quando ocorrem sensíveis às demandas do grupo e não voltadas exclusivamente ao seu filho, como, por exemplo, quando há a pressão dos pais para que seu filho seja titular.

De Rose Jr. (1992) observou que, apesar da diversidade de aspectos que influenciam a educação das crianças, a participação dos pais possui um papel diferencial, principalmente quando as crianças estão iniciando no esporte, afinal, são os pais que mais convivem com seus filhos e são eles quem os conhecem melhor do que ninguém.

Todas as dez crianças que pesquisamos disseram que durante os jogos não conseguem visualizar seus pais nas arquibancadas. No entanto, todas elas afirmaram gostar de saber que eles estão presentes, disseram também que gostam que eles acompanhem os treinos, ensaiem músicas, se façam presentes e torçam nos dias de jogos.

\footnotetext{
7 Um texto que não trata da questão esportiva, mas que mostra um pouco da tradição e da complexidade desse tema é de Pierre Bourdieu "As contradições da herança", 1997. No campo da psicologia esportiva infantil, os estudos que abordam esse tema são raros e mais escassos ainda são aqueles feitos a partir de referências como Vygotsky (1988), Wallon (1975) e Melanie Klein (1997), por exemplo.
}

Movimento, Porto Alegre, v.13, n. 02, p.77-90, maio/agosto de 2007. 
Esta constatação (de que as crianças gostam da presença dos seus pais) de certa forma se distancia daquilo que certos autores vêm apontando. Machado (1997), por exemplo, coloca que há uma tendência de os filhos-atletas se sentirem incomodados com a presença dos pais em treinos e jogos. Esta controvérsia mostra o cuidado que devemos ter em não fazer afirmações genéricas e aponta para a necessidade de pesquisas empíricas mais detalhadas, que levem em conta categorias como a idade e a classe social das crianças, por exemplo.

Mais do que uma simples constatação, a afirmação positiva das crianças no que diz respeito à presença dos seus pais deve ser entendida como uma "dica", ou melhor, como um indicador didáticopedagógico para os professores de escolinhas esportivas. Todas as vezes em que os professores se sentirem incomodados com a presença dos pais é importante lembrar o quanto ela é importante para os seus alunos. Nesse sentido, por mais difícil que às vezes possa parecer, a estratégia mais indicada é buscar a melhor interação possível com os pais, e apostar na constituição de um trabalho conjunto entre pais e professores, deixando claras as diferenças e as responsabilidades de cada um. Esse método é uma construção própria, como procurou construir o professor a quem entrevistamos:

Isso pra mim foi um caminho também, caminho
que a gente vai aprendendo. Eu já tive períodos de
dar muito assunto aos pais e também tive períodos
de não dar assunto nenhum. Tive extremos. E, na
verdade, nenhum desses dois resolveu a situação.
Mas hoje eu tenho uma boa relação com os pais,
eu deixo claro desde o princípio qual é a minha
forma de trabalho, qual é a linha, a filosofia que eu
vou seguir. (J. D. F., 2004).

Por último, cabe deixar claro que dificilmente os pais tomariam qualquer atitude que pudesse prejudicar seus filhos ou outras crianças. Na maioria das vezes, as atitudes questionáveis ocorrem ou por falta de um maior conhecimento psicopedagógico ou pelas tensões advindas das disputas futebolísticas. Porém, como destaca Melanie Klein, é importante nos lembrarmos que as experiências emocionais, principalmente na infância, possuem um sabor, um sentido e um valor bastante especial. Para essa autora, comentam Elias e Elizabeth Barros (2005, p.10):

Movimento, Porto Alegre, v.13, n. 02, p.77-90, maio/agosto de 2007. 
[...] o significado emocional das experiências não nos é dado por uma faculdade independente idealizada como razão, uma faculdade capaz de operar fora de uma zona de conflitos, mas pela organização das emoções que vão colorir nossa razão transformando-a em crenças e percepções.

Por isso, prosseguem os autores, “[...] para Melanie Klein e seus seguidores as pessoas não sofrem apenas de carências, traumas ou repressões, elas sofrem também de falta de experiências emocionais que propiciem um desenvolvimento/crescimento" (BARROS, 2005, p. 11-12).

Parental relationships in indoor soccer: the
case of the Paulista Futebol Clube indoor soccer
Abstract: This research has the aim of analyzing the
participation and the practices of intervention of parents
along with the indoor Soccer "futsal" schools. In order
to do the study is has been used the method of
"Observant Participation", and some principles from
oral history. The empirical focus of the study was the
beginner team (ages 8 and 9) of the Paulista Futebol
Clube. Nevertheless the disproportionate interference
of the parents in the coach duty we have come to the
conclusion that it possesses certain positive points in
the children's education, being the coaches responsible
for the challenge of learning how to deal with it.
Keywords: Indoor Soccer. Child. Parent-child
Relations. Competitive behavior.

Los padres y el fútbol de sala: el caso del Paulista Futebol Clube

Resumen: Ésa investigación tiene como objetivo analizar la participación y las prácticas de la intervención de los padres junto a las escuelas de fútbol de sala "fútsal". Para realizar el estudio utilizamos el método de la "Participación del Observador" y algunos principios oriundos de la historia oral. El foco empírico del estudio fue el equipo de principiantes (8 y 9 años) del Paulista Futebol Clube. Aunque la participación desmesurada de los padres y su intervención en el trabajo del profesor, concluimos que ella añade ciertas positividades fundamentales en la educación infantil y queda a los profesores el desafío de arreglárselas.

Palabras clave: Fútbol de sala. Niño. Relaciones Padres-hijo. Conducta competitiva. 


\section{REFERÊNCIAS}

AMADO, J; FERREIRA, A. (coord.). Usos \& abusos da história oral. Rio de Janeiro: Editora da Fundação Getulio Vargas, 1998.

BARROS, E.; BARROS, E. Significado de Melanie Klein. Revista Viver Mente \& Cérebro. Pinheiros: Ediouro, Segmento-Duetto, 2005. p. 6-15. (Coleção memória da psicanálise, n. 3)

BENTO, J. O. A criança no treino e desporto de rendimento. Revista Kinesis, Santa Maria, v. 1, n.5, p. 9-35, 1989.

BOURDIEU, P. As contradições da herança. In: LINS, Daniel (org). Cultura e subjetividade: saberes nômades. Campinas: Papirus, 1997. p 7-18.

DECCACHE-MAIA, E. Esporte e juventude no Borel. Revista Estudos Históricos, Rio de Janeiro, v. 13 n. 23, p. 192-206, 1999

DELEUZE, G. Conversações. Rio de Janeiro: Ed. 34, 1992.

DE ROSE JR. D. Considerações sobre a participação da criança no processo competitivo. In: SIMPÓSIO DE PSICOLOGIA DO ESPORTE, 1, Anais... São Paulo: EEFUSP, 1992. p. 27-33.

FERREIRA, M. de M. (org.). História oral: desafios para o século XXI. Rio de Janeiro: Fiocruz/Casa de Oswaldo Cruz/CPDOC, 2000.

FOUCAULT, M. Sobre a prisão. In: FOUCAULT, M. Microfísica do Poder. 8. ed. Rio de Janiero: Graal, 1979. p. 129-143.

GATTI, B. A. A construção da pesquisa em educação no Brasil. Brasília: Plano, 2002.

GOMES, R. A relação entre pais e filhos no desporto. Disponível em: $<$ ttp/ /www.filhosonline.com.br>. Acesso em: 25 jan., 2004.

GUEDES, S. L. A construção do corpo masculino nas escolinhas de futebol. In: GUEDES, S. L. O Brasil no campo de futebol: estudos antropológicos sobre os significados do futebol brasileiro. Niterói: EDUFF, 1988. p. 117-136.

JÓDAR, Francisco; GÓMEZ, Lucía. Experimentar o presente: sobre a conformação de novas identidades. Educação \& Realidade: Dossiê Michel Foucault, Porto Alegre, v. 29, n. 1, p.139-153, jan./jun. 2004.

KLEIN, M. A psicanálise de crianças. Rio de Janeiro: Imago, 1997.

MACHADO, A. A. Psicologia do esporte: temas emergentes. Jundiaí: Ápice, 1997.

PIMENTA, M. Novos processos de formação de jogadores de futebol e o fenômeno das "escolinhas": uma análise crítica do possível. In: ALABARCE, P. (Org.). Peligro de Gol: estudios sobre deporte y sociedade en América Latina. Buenos Aires: CLACSO, 2000. p. 75-97. 
REZER, R.; SAAD, M. Futebol e futsal: possibilidades e limitações da prática pedagógica em escolinhas. Chapecó: Argos, 2005.

RIGO, L. C. et al. Futebol à tardinha: notas sobre educabilidade. In: RIGO, L. C.; PARDO, E. R.; THOMAZ, F. O. (Org.) Além da Universidade... Ijuí: UNIJUÍ, 2006. p. 47-62.

SANTANA, W. C. Metodologia da Participação: Futsal. Londrina: Lido, 1996.

TEVES, N. Jogos Escolares: A Responsabilidade Social do Professor de Educação Física. In: VOTRE, Sebastião J. et al (org.), Cultura, Atividade Corporal \& Esporte. Rio de Janeiro: Editora Central da Universidade Gama Filho, 1995. p. 45-54.

THOMPSON, P. A Voz do Passado: História Oral. Rio de Janeiro: Paz e Terra, 1992.

TRIVIÑOS, A. N. S. Introdução à Pesquisa em Ciências Sociais: a pesquisa qualitativa em Educação. São Paulo: Atlas, 1987.

VOSER, R. C. Análise das intervenções pedagógicas em Programas de Iniciação ao Fustal. Porto Alegre: Universidade Federal do Rio Grande do Sul, 1999.

VYGOTSKY, L. S.; LURIA, A. R.; LEONTIEV, A. N. Linguagem, Desenvolvimento e aprendizagem. São Paulo: Ícone, 1988.

WACQUANT, L. Corpo e Alma: Notas etnográficas de um aprendiz de boxe. Rio de Janeiro: Relume Dumará, 2002.

WALLON, H. Psicologia e educação da infância. Lisboa: Estampa, 1975.

\section{Entrevistas}

F. P. pai de D. P. A opinião de pais sobre as escolinhas de futsal. Pelotas, 19 de fevereiro de 2004. Entrevista concedida a Gabriel Barros da Cunha e Gicele de Oliveira Karini.

C. A. pai de B. A. A opinião de pais sobre as escolinhas de futsal. Pelotas, 14 de abril de 2004. Entrevista concedida a Gabriel Barros da Cunha e Gicele de Oliveira Karini.

C. P. mãe de D. P. A opinião de pais sobre as escolinhas de futsal. Pelotas, 20 de abril de 2004. Entrevista concedida a Gabriel Barros da Cunha e Gicele de Oliveira Karini.

J. D. F. Professor de Futsal. A opinião de pais sobre as escolinhas de futsal. Pelotas, 14 de junho de 2004. Entrevista concedida a Gabriel Barros da Cunha e Gicele de Oliveira Karini.

Movimento, Porto Alegre, v.13, n. 02, p.77-90, maio/agosto de 2007. 